\title{
Calculation and comparative analysis of the mean energy expended per ion pair by electrons in water and hydroxyl radical
}

\author{
Yurii V. Kovtun \\ National Science Center \\ Kharkov Institute of Physics and Technology, \\ Akademicheskaya St. 1, \\ 61108 Kharkov, Ukraine \\ E-mail:Ykovtun@kipt.kharkov.ua
}

\begin{abstract}
Researches of physical and chemical processes occurring in water during the interaction with particles (electrons, ions, photons, etc.) are interesting for a wide range of physical and applied problems in astrophysics, radiation physics, chemistry, medicine and biology, plasma physics, and other branches of science and technology. One of the directions, which invokes a considerable interest in low-temperature plasma physics and its application technologies, includes researches of electric discharges in the liquid and above its surface. While developing any technology, in which electric discharges in a liquid and above its surface will be used, the determination of the main channels of energy expenditure and, accordingly, the total amount of energy expenditure comprises an important task. One of the main channels of energy expenditures are those for ionization by an electron impact, or the so-called ionization cost $W$. The cost of ionization by an electron impact is usually assumed to be a certain mean value of energy spent by an electron for the formation of an ion-electron pair in the substance.

The paper presents the results of calculations and comparison of the cost of ionization of water and hydroxyl radical by an electron impact on the basis of two models. The calculations based on the model with the passage of a monoenergetic electron flow (beam) with an energy of 14-1000 eV through the medium show that for an electron energy of $1000 \mathrm{eV}$, the ionization cost for the water molecule is $W=25.26 \mathrm{eV}$ and $W=21.65 \mathrm{eV}$ for the hydroxyl radical. The results of calculations show that the ionization cost for the model taking into account the electron energy distribution function in a plasma with $T_{e}=100 \mathrm{eV}$, this value is $W=16.85 \mathrm{eV}$ for the water molecule and $W=14.5 \mathrm{eV}$ for the hydroxyl radical.
\end{abstract}

Keywords: plasma, cost of ionization, hydroxyl radical, electron impact, water molecule

\section{INTRODUCTION}

The studies of electric discharges in liquid water and over its surface, and also in water vapour are of significant interest in low-temperature plasma physics and its application technologies [1-3]. It is pertinent to note that interest in physical and chemical processes occurring in water is also specified by the studies into the effects of ionizing radiation on biological objects 
in the fields of radiation physics, chemistry, biology and medicine. The interaction of charged particles and radiation with the water molecule, the occurrence of chemical and plasma-chemical processes result in the generation of water decomposition products, one of them being the hydroxyl radical $(\mathrm{OH})$, which is formed during electric discharges [1-3]. The formation of $\mathrm{OH}$ $\left(\mathrm{OH}^{+}\right)$in water can be the result of numerous processes $[2,3]$, which can proceed with the participation of electrons: $e+\mathrm{H}_{2} \mathrm{O} \rightarrow \mathrm{OH}+$ product; photons: $h v+\mathrm{H}_{2} \mathrm{O} \rightarrow \mathrm{OH}+$ product; positive and negative ions: $\mathrm{M}^{+}+\mathrm{H}_{2} \mathrm{O} \rightarrow \mathrm{OH}+$ product, $\mathrm{M}^{-}+\mathrm{H}_{2} \mathrm{O} \rightarrow \mathrm{OH}+$ product; neutral atoms and molecules: $\mathrm{M}+\mathrm{H}_{2} \mathrm{O} \rightarrow \mathrm{OH}+$ product. Similar processes will take place with the participation $\mathrm{H}_{2} \mathrm{O}^{*}$, $\mathrm{H}_{2} \mathrm{O}^{+}$as well as other compounds resulting from chemical and plasma-chemical processes.

When developing any technology with the use of electric discharges in water, it is of current interest to determine the main channels of energy expenditure and overall expenditure of energy. The problem is rather complicated, and in the general case the energy expenditure is dependent on specific technological conditions. However, in principle, it is possible to determine one of the main channels of energy expenditure, namely, the expenditure of energy for plasma generation. The main factors responsible for the finite energy expenditure value in generating plasma with required parameters are the processes that take place in the plasma, such as ionization, recombination, diffusion, charge exchange, etc. Out of them, we have chosen to consider the energy expenditure for ionization by electron impact or the so-called "ionization cost" $W$. This "cost" is generally understood to be a certain mean value of energy spent by the electron for the formation of an ion-electron pair in the substance.

There are different models for calculating the ionization cost, which may be conditionally divided into two basic approaches. In the first approach, the ionization cost value is estimated from the consideration of elementary processes associated with the passage of a monoenergetic electron flow (beam) through the medium. This approach is fully justified when the ionization of the medium is mainly contributed by the primary electron flow (beam). In the second approach, the ionization cost involves the elementary processes occurring in the plasma, where the electrons have the energy distribution function. In any case, there is always necessity of knowing both the threshold energy values and the cross sections for the elementary processes, which in turn have an effect on the finite ionization cost. Irrespective of the model used, the ionization cost calculation always presents an approximation to the real value.

So, in view of the above, it is of interest to calculate and compare the costs of $\mathrm{H}_{2} \mathrm{O}$ and $\mathrm{OH}$ ionization by electron impact on the basis of two models; the more so, as the calculations of $\mathrm{OH}$ ionization costs are absent in literature. We here consider both approaches and using them as the base carry out numerical calculations. The present work is a continuation of our earlier studies [4-6].

\section{ELECTRON COLLISIONS WITH MOLECULES}

Unlike the electron-atom collision, the electron-molecule collision is characterized by a large number of possible processes that would result in the energy loss by the incident electron. Among these processes, it stands to mention the elastic electron-molecule collision, the electron-impact excitation of rotational and vibrational levels of the molecule, the electronic state excitation of the molecule, the molecule ionization by electrons, etc. Some of the processes arising from collisions of electrons with the water molecule and hydroxyl radical are presented in Fig. 1. The formation of $\mathrm{OH}$, and also of $\mathrm{OH}^{+}$and $\mathrm{OH}^{-}$ ions may proceed in several channels (see Fig. 1). The processes have different threshold energies, below which the process will not occur. For example, the ionization threshold energy is numerically equal to the molecule ionization potential $12.621 \mathrm{eV}$ for $\mathrm{H}_{2} \mathrm{O}$, and $13.017 \mathrm{eV}$ for $\mathrm{OH}$ [8]. If the energy is above the threshold energies, the probability of elementary process occurrence depends on the cross-sections. The ionization cost calculations take into account, irrespective of the model employed, the processes of electron-molecule collisions and their cross-sections. Let us consider in greater detail these processes and their cross-sections for the $\mathrm{OH}$ molecule. It is noteworthy that the ionization cost value should not be lower than the ionization potential. 


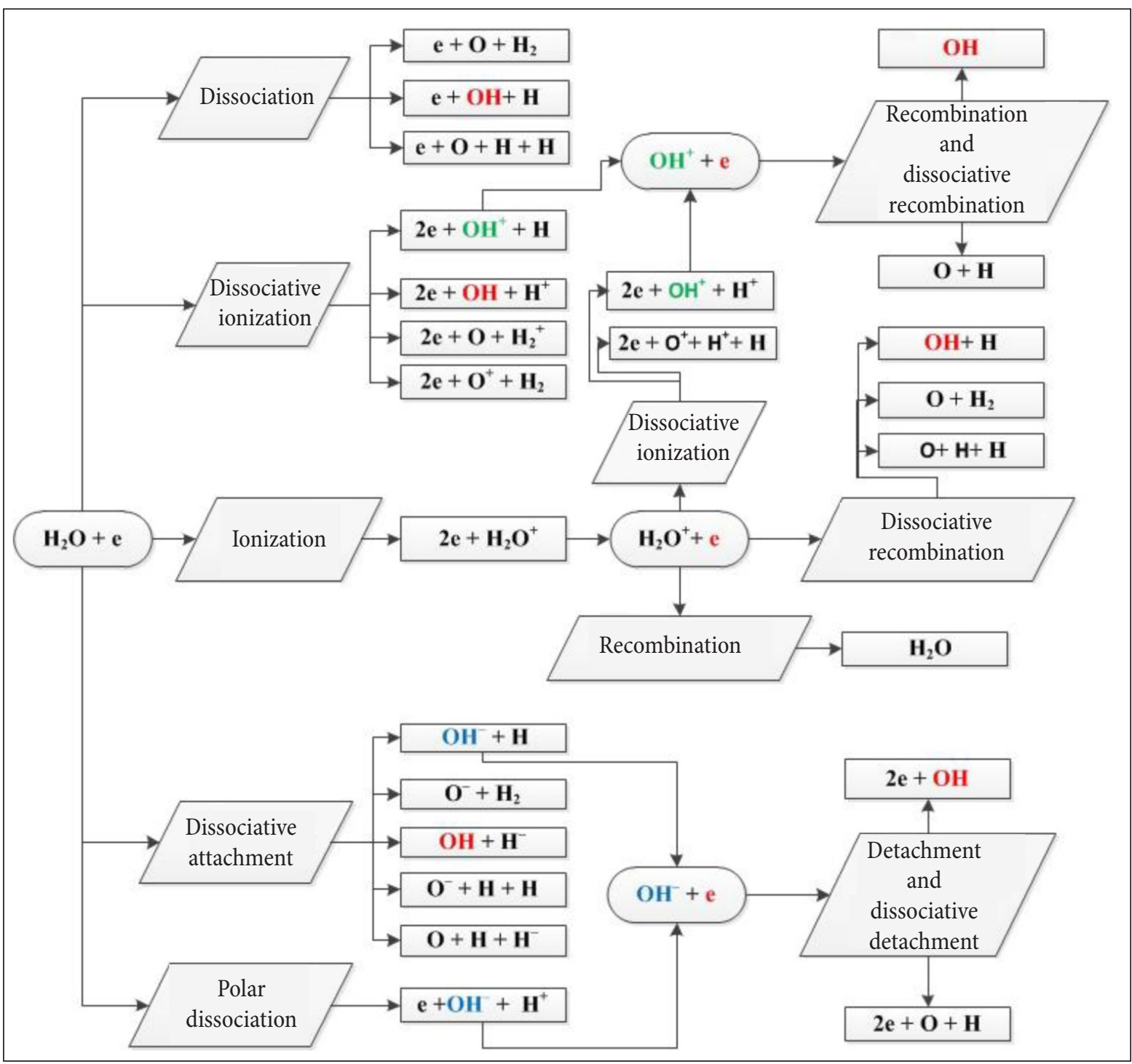

Fig. 1. Electron collisions with water molecule and hydroxyl radical

\section{ELASTIC SCATTERING CROSS-SECTIONS}

Elastic electron-molecule collision causes the momentum transfer to the molecule and scattering of electron beams as they pass through the matter. In contrast to other processes, the given process has no threshold character. Theoretical calculations of the total scattering cross-section $\sigma_{\text {tot }}$ (the sum of the cross-section $\sigma_{e l}$ for elastic scattering and the total inelastic-scattering cross-section $\left.\sigma_{i n e l}\right)$ for electron collisions with hydroxyl radical can be found in refs. [9-11], where the authors calculated the $\sigma_{\text {tot }}$ values for the electron energy range from 30 to $5000 \mathrm{eV}$ [9], 50 to $2000 \mathrm{eV}$ [10], and 1 to $500 \mathrm{eV}$ [11]. The cross-sections for elastic electron-OH scattering were calculated in pa- per [11] for the electron energy ranging from 1 to $500 \mathrm{eV}$.

\section{Vibrational excitation cross-sections}

Inelastic electron-molecule collisions can result in the excitation of both rotational levels and rotational-vibrational levels, and also of electronic levels with simultaneous excitation of rotational and vibrational levels. The vibrational excitation plays an essential role in the discharges in the molecular gas medium, as it is one of the main mechanisms of energy transfer from electrons to the molecules. The cross-sections for rotational level excitation of $\mathrm{OH}$ are absent in the literature. The authors of ref. [12] have calculated the cross-section for the vibrational level excitation $v=1$ (electronic 
ground state $\mathrm{X}^{2} \Pi$ ) by means of the R-matrix technique for the electron energy up to $3 \mathrm{eV}$. The data on the excitation cross-sections for other $\mathrm{OH}$ vibrational levels are not available in the literature.

\section{Excitation cross-sections}

Electron transitions in the molecule may take place as a result of both internal disturbance (spontaneous emission) and external disturbance (due to electron impact, radiation absorption), in which case the internuclear separation and the rate of relative nuclear motion change only slightly (the Frank-Condon principle) [7]. This leads to different variants of the electron transition depending on the curve shapes of initial- and final-state potential energies, e.g. molecule formation in the stable excited state; molecule dissociation, etc. The $\mathrm{OH}$ electronic levels and the energies of vertical transition from the ground level (data taken from ref. [13]) are presented in Table 1. The same table lists the oscillator strength values [13]. The cross-sections $\sigma_{\text {inel }}$ for inelastic electron-hydroxyl radical collisions (the sum of the (total) excitation cross-section $\sigma_{e x}$ and the (total) ionization cross-section $\sigma_{i}^{\text {tot }}$ ) were calculated in the works [9] (up to $5000 \mathrm{eV}$ ), [10] (up to $2000 \mathrm{eV}$ ) and [11] (up to $500 \mathrm{eV}$ ). The excitation rate constants of the electron levels $\mathrm{A}^{2} \Sigma^{+}$and $\mathrm{B}^{2} \Sigma^{+}$were calculated in ref. [14] on the basis of the WTCS (Weighted Total Cross-Section) model over the temperature range from 1500 to $15000 \mathrm{~K}$. As it is obvious, the literature data on the electron-level excitation cross-sections for $\mathrm{OH}$ are far from being complete. As to the available data, they are insufficient for performing calculations of the energy expenditure for ionization. Therefore, we shall calculate here the $\mathrm{OH}$ electron-level excitation cross-sections, using the empirical Drawin formula $[15,16]$ :

$$
\sigma_{e x}=4 \pi a_{0}^{2}\left(R / E_{i j}\right)^{2} f_{i j} \frac{X_{i j}-1}{X_{i j}^{2}} \ln \left(1.25 \beta_{i j} X_{i j}\right),(1)
$$

where $X_{i j}=E / E_{i j}, E$ (in $\mathrm{eV}$ ) is the kinetic energy of the primary electrons, $E_{i j}($ in $\mathrm{eV}$ ) is the energy difference between levels $i$ and $j\left(E_{i j}=E_{j}-E_{i}\right), f_{i j}$ is the oscillator strength, $\beta_{i j}$ denotes level-dependent coefficients $\left(\beta_{i j} \approx 1\right), a_{0}$ is the Bohr radius, and $R$ is the Rydberg energy. For the calculations, we took the transition energy and oscillator strength values from ref. [13] (see Table 1). Our calculation data on the excitation cross-sections for 13 electron levels of $\mathrm{OH}$ are presented in Fig. 2. As it is shown
Table 1. Vertical excitation energies and oscillator strengths of transitions between the ground state and excited states of $\mathrm{OH}$ [13]

\begin{tabular}{ccc}
\hline State & $\boldsymbol{E}_{\text {ex }} \mathbf{e V}$ & $\boldsymbol{f}_{\boldsymbol{i j}}$ \\
\hline $\mathrm{A}^{2} \Sigma^{+}$ & 4.05 & $1.1 \cdot 10^{-3}$ \\
\hline $\mathrm{B}^{2} \Sigma^{+}$ & 10.98 & $1.3 \cdot 10^{-2}$ \\
\hline $\mathrm{C}^{2} \Sigma^{+}$ & 13.77 & $3 \cdot 10^{-3}$ \\
\hline $1^{2} \Sigma^{-}$ & 7.2 & $3.1 \cdot 10^{-2}$ \\
\hline $\mathrm{D}^{2} \Sigma^{-}$ & 9.28 & $1 \cdot 10^{-2}$ \\
\hline $3^{2} \Sigma^{-}$ & 10.11 & $6.7 \cdot 10^{-4}$ \\
\hline $4^{2} \Sigma^{-}$ & 10.81 & $1.1 \cdot 10^{-2}$ \\
\hline $5^{2} \Sigma^{-}$ & 11.18 & $1.2 \cdot 10^{-2}$ \\
\hline $2^{2} \Pi$ & 9.74 & $4.2 \cdot 10^{-4}$ \\
\hline $3^{2} \Pi$ & 11.4 & $9.2 \cdot 10^{-2}$ \\
\hline $4^{2} \Pi$ & 12.03 & $1.2 \cdot 10^{-3}$ \\
\hline $5^{2} \Pi$ & 13.08 & $1.7 \cdot 10^{-2}$ \\
\hline $1^{2} \Delta$ & 9.33 & $1.9 \cdot 10^{-2}$ \\
\hline $2^{2} \Delta$ & 11.76 & $6.5 \cdot 10^{-3}$ \\
\hline $3^{2} \Delta$ & 12.6 & $9.7 \cdot 10^{-5}$ \\
\hline & &
\end{tabular}

in Fig. 2, the calculated cross-section values are no more than $1.4 \cdot 10^{-17} \mathrm{~cm}^{-2}$. According to ref. [7], the cross-section for electron level excitation with simultaneous excitation of vibrational levels of diatomic molecules is equal to

$$
\sigma\left(n, v \rightarrow n^{\prime}, v^{\prime}\right)=F_{v v^{\prime}}^{n n^{\prime}} \sigma_{e x}\left(n \rightarrow n^{\prime}\right),
$$

where $F$ is the Frank-Condon factor. Since there are no comprehensive data on the Frank-Condon

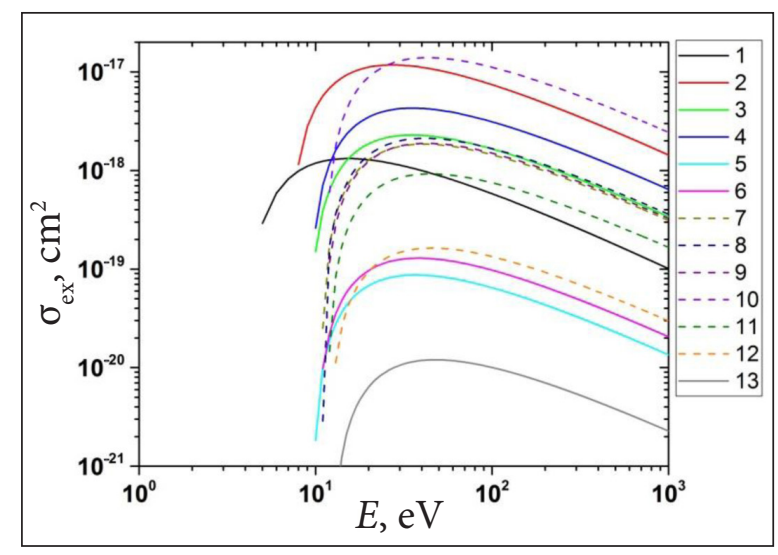

Fig. 2. Electron impact excitation cross-sections for the electronic state of OH. $1-A^{2} \Sigma^{+} ; 2-1^{2} \Sigma^{-} ; 3-D^{2} \Sigma^{-} ; 4-1^{2} \Delta ; 5-2^{2} \Pi ; 6-3^{2} \Sigma^{-}$; $7-4^{2} \Sigma^{-} ; 8-B^{2} \Sigma^{+} ; 9-5^{2} \Sigma^{-} ; 10-3^{2} \Pi ; 11-2^{2} \Delta ; 12-4^{2} \Pi ; 13-3^{2} \Delta$ 
factor for the electronic-vibrational transitions, expression (2) was not used in the present calculations.

\section{TOTAL IONIZATION CROSS-SECTION}

For the first $\mathrm{OH}$ ionization potential there is a corresponding energy of $13.017 \mathrm{eV}$ [8], which is equal to the transition in ground-state $\mathrm{X}^{3} \Sigma^{-}$ the $\mathrm{OH}^{+}$ion. The process of dissociative $\mathrm{OH}$ ionization is also possible; it proceeds with the formation of ionic and neutral fragments. Theoretical calculations of the total cross-section for the hydroxyl radical electron-impact ionization were conducted in the works [10] (up to $2000 \mathrm{eV}$ ), [14] (up to $100 \mathrm{eV}$ ), [17] (up to $200 \mathrm{eV}$ ). The experimental data on the cross-section for the OD (Hydroxyl-d, deuterated OD radical) electron-impact ionizationwere obtained in [18] (up to $200 \mathrm{eV}$ ). At the same time, no data can be found in the literature on the differential $\mathrm{OH}$ ionization cross-section. These data are needed for calculating energy expenditures for ionization. Therefore, we have calculated here the total cross-section for $\mathrm{OH}$ electron-impact ionization using the binary-encounter-Bethe (BEB) model [19], which also enables one to calculate the differential ionization cross-sections. According to this model, total ionization cross-section is given by

$$
\begin{aligned}
& \sigma_{i}^{t o t}=\frac{4 \pi a_{0}^{2} N(R / B)^{2}}{x+(U / B)+1}\left\{\frac{1}{2} Q\left(1-\frac{1}{x^{2}}\right) \ln x\right. \\
& \left.+(2-Q)\left[\left(1-\frac{1}{x}\right)-\frac{\ln x}{x+1}\right]\right\},
\end{aligned}
$$

where $x=E / B, Q \approx 1, B$ is the orbital binding energy, eV; $U$ is the orbital kinetic energy, eV; $N$ is the orbital electron occupation number. The atomic data for $\mathrm{OH}(B, U, N)$ used in the calculations were taken from work [20]. The calculation results are presented in Fig. 3 along with the integrated data on the cross-sections for the following processes: elastic collisions (the data of ref. [11] were interpolated to the region of low $(<1 \mathrm{eV})$ and "high" (500 eV) electron energies); vibrational level excitations, $v=1$ [12]; and also the total cross-section for electronic level excitation (the present work).

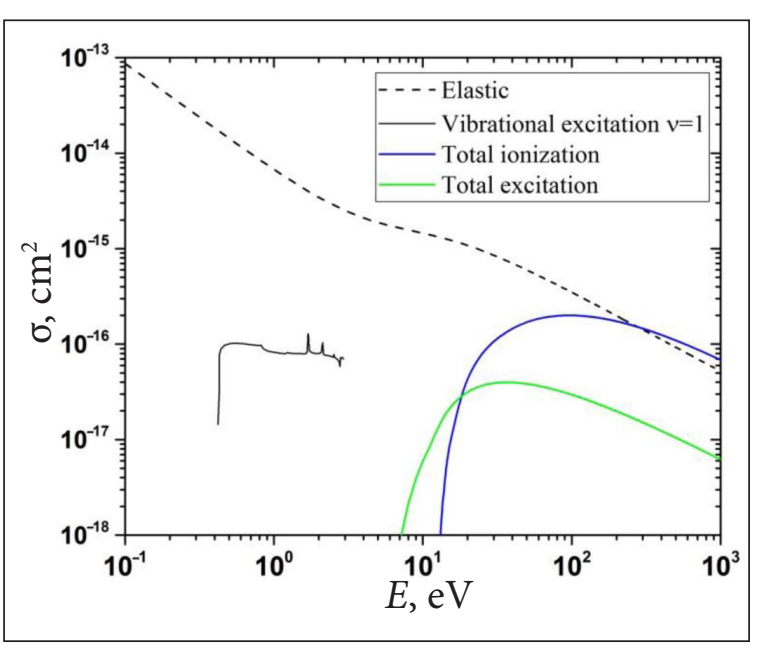

Fig. 3. Cross-section set for $\mathrm{e}+\mathrm{OH}$

\section{MEAN ENERGY EXPENDED PER ION PAIR BY ELECTRONS}

\section{Model with the passage of a monoenergetic} electron flow (beam) passes through a medium The given model deals with the total energy loss by the monoenergetic electron flow (beam) as it passes through the medium, the energy loss being due to ionization cascades. The mean energy expended for the ion-electron pair formation, i.e. the ionization cost, is determined by the expression

$$
W=\frac{E}{\left\langle N_{i}\right\rangle}
$$

where $E$ is the primary electron energy, $\mathrm{eV} ;\left\langle N_{i}\right\rangle$ is the average number of ions resulting from electron-molecule collisions.

To calculate the cost of water molecule ionization by the monoenergetic beam, we use the CSDA-based model proposed in ref. [21] (CSDA stands for the continuous-slowing-down approximation). In the given model, the cost of the molecule electron-impact ionization with due account for the ionization by secondary electrons is given by

$$
W(E)=\frac{E}{\sum_{n} N_{i, n}(E)},
$$

where $N_{i, n}(E)$ is the number of ions produced by the $n$-th generation of electrons ( $n=0$ denotes primary electrons). The number of ions produced by the primary electrons is equal to 


$$
N_{i, 0}(E)=\int_{E_{i z}}^{E} \frac{\sigma_{i}^{t o t}(E)}{L(E)} d E,
$$

where $\sigma_{i}^{\text {tot }}(E)$ is the integrated cross-section for ionization, $\mathrm{cm}^{2}, L(E)$ is the energy loss function, $\mathrm{cm}^{2} \cdot \mathrm{eV}$. The function $L(E)$ is the sum of productions of process cross-sections by energy losses in all the energy loss channels and is determined as

$$
\begin{aligned}
& L(E)=\sum_{i} \sigma_{r, i} E_{r, i}+\sum_{j} \sigma_{v, j} E_{\mathrm{v}, j}+ \\
& +\sum_{k} \sigma_{\text {exc, } k} E_{\text {exc }, k}+\sum_{n} \sigma_{i z, n} E_{i z, n}+ \\
& +\sigma_{\text {elas }} \frac{3 m_{e}}{m_{M}} E+\int_{n}^{\left(E-E_{i z}\right) / 2} \varepsilon \cdot \sigma(E, \varepsilon) d \varepsilon,
\end{aligned}
$$

where $\sigma_{r, i}, \sigma_{v, j}, \sigma_{e x c, k}, \sigma_{i z, n}, \sigma_{\text {elas }}$ are, respectively, the cross-sections for excitation of rotational, vibrational, electronic levels in the molecule; for ionization (dissociative ionization), and for elastic collisions, $\mathrm{cm}^{2} ; E_{r, i}, E_{v, j}, E_{e x c, k} E_{i z, n}$ are, respectively, the excitation energies of rotational, vibrational, electronic levels of the molecule, the ionization (dissociative ionization) energy, $\mathrm{eV} ; m_{e}, m_{M}$ are the electron and molecule masses, correspondingly, $\mathrm{kg} ; \sigma(E, \varepsilon)$ is the differential ionization cross-section, $\mathrm{cm}^{2} / \mathrm{eV}$; $\varepsilon$ is the secondary electron energy, $\mathrm{eV}$.

The number of ions produced due to ionization by secondary electrons is determined as

$$
\begin{aligned}
& N_{i, 1}(E)=\int_{E_{i z}}^{\left(E-E_{j z}\right) / 2} n(E, \varepsilon) N_{i, 0}(\varepsilon) d \varepsilon, \\
& N_{i, 2}(E)=\int_{3 \cdot E_{i z}}^{\left(E-E_{j z}\right) / 2} n(E, \varepsilon) N_{i, 1}(\varepsilon) d \varepsilon,
\end{aligned}
$$

where $n(E, e)$ is the quantity of secondary electrons of energy $\varepsilon$ produced by primary electrons of energy $E$, which is given by

$$
n(E, \varepsilon)=\int_{2 \cdot \varepsilon+E_{i z}}^{E} \frac{\sigma(E, \varepsilon)}{L(E)} d E .
$$

\section{Model taking into account the electron energy distribution}

In a partially ionized plasma, the ionization may go either through a direct electron transition to the ground level of the molecular ion, or through the cascade transitions by stepwise excitation of electronic-vibrational levels of the molecule by electrons (stepwise ionization). In this case, it is necessary to take into account all the processes associated with direct/cascade/nonradiative transitions. Accordingly, the ionization cost depends not only on temperature, but on electron density as well. In the general case, the ionization cost can be determined from the expression [22]:

$$
\begin{aligned}
& W\left(T_{e}\right)= \\
& =\frac{\sum_{n>m} f_{n} \alpha(n \rightarrow m) \Delta E_{n m}+\sum_{n} f_{n} K_{n \rightarrow \infty}\left(T_{e}\right) E_{i z}}{\sum_{n} f_{n} K_{n \rightarrow \infty}\left(T_{e}\right)},
\end{aligned}
$$

where the sum over all the levels $n, \alpha(n \rightarrow m)$ is the radiative decay rate from $n$ to $m, \Delta E_{n m}$ (in $\mathrm{eV}$ ) is the energy difference between levels $n$ and $m, K_{n \rightarrow \infty}$ is the ionization rate coefficient of level $n, f_{n}$ is the fraction of atoms in state $n$.

For molecules, the ionization cost calculation taking into account all the transitions mentioned becomes strongly complicated. Therefore, we shall make use of the model proposed in ref. [23], where the cascade/nonradiative transitions are not considered. The model gives a sufficient approximation to the experimental results obtained in a number of works [24, 25]. Taking into consideration the processes of dissociative ionization, the atom ionization cost for the molecule can be estimated from the formula [5]:

$$
\begin{aligned}
& W\left(T_{e}\right)=\sum_{j} E_{i z, j} \frac{K_{i z, j}\left(T_{e}\right)}{K_{i z}\left(T_{e}\right)}+ \\
& +\sum_{i} E_{e x c, i} \frac{K_{e x c, i}\left(T_{e}\right)}{K_{i z}\left(T_{e}\right)}+\frac{K_{e l a s}\left(T_{e}\right)}{K_{i z}\left(T_{e}\right)} \frac{3 m_{e}}{m_{i}} T_{e}
\end{aligned}
$$

where $E_{e x c, i}$ and $K_{e x c, i}$ denote, respectively, the energy (in eV) and the excitation rate constants (in $\mathrm{cm}^{3} / \mathrm{s}$ ) of rotational, vibrational and electronic levels of the molecule; $E_{i z, j}$ and $K_{i z, j}$ are the energy (in $\mathrm{eV}$ ) and the rate constant (in $\mathrm{cm}^{3} / \mathrm{s}$ ) of dissociative ionization, $K_{\text {elas }}\left(\right.$ in $\mathrm{cm}^{3} / \mathrm{s}$ ) is the rate constant of elastic collisions, where $m_{e}$ is the electron mass, $m_{i}$ is the ionic mass, $\mathrm{kg}$. 


\section{RESULTS AND DISCUSSION}

The calculation of the $\mathrm{OH}$ ionization cost within the framework of the model, which considers the passage of a monoenergetic electron flow (beam) through the medium, was carried out by formulas (5) to (10). In the calculations, we have used the process cross-sections shown in Figs. 2 and 3. The threshold energy of the processes was taken from refs. $[8,12,13]$. The differential cross-section for the $\mathrm{OH}$ ionization was calculated on the basis of the BEB model [19] with due account of the atomic data $(B, U, N)[20]$. The calculated data are presented in Fig. 4. For comparison, Fig. 4 shows the water ionization cost as a function of the electron energy [4-6]. The comparison between the calculated ionization costs for $\mathrm{H}_{2} \mathrm{O}$ and $\mathrm{OH}$ (see Fig. 4) shows a somewhat higher $W$ value for $\mathrm{H}_{2} \mathrm{O}$ than for $\mathrm{OH}$. At electron energy of $1000 \mathrm{eV}$ the $W$ value was calculated to be $25.26 \mathrm{eV}$ and $21.65 \mathrm{eV}$ for $\mathrm{H}_{2} \mathrm{O}$ and $\mathrm{OH}$, respectively.

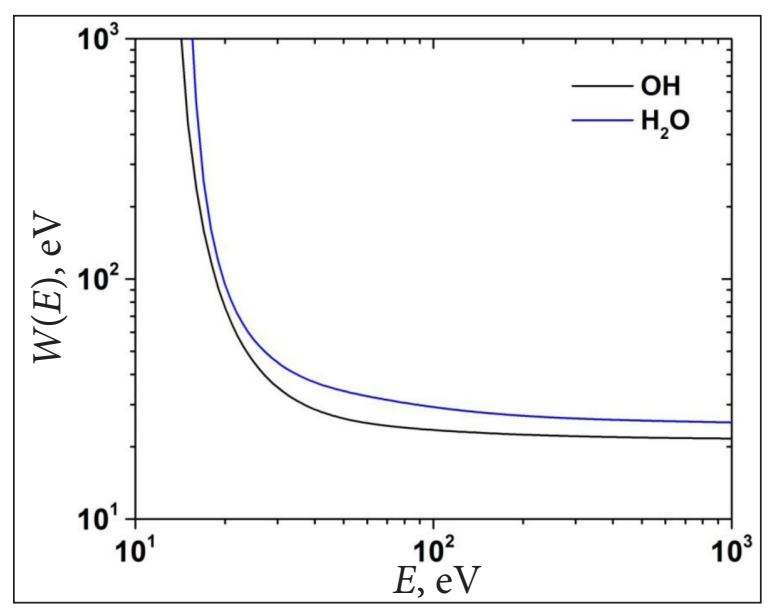

Fig. 4. Mean energy per electron-ion pair for $\mathrm{OH}_{\text {and }} \mathrm{H}_{2} \mathrm{O}$ on the primary electron energy

The $\mathrm{OH}$ ionization cost within the framework of the model, which includes the electron energy distribution function (EEDF) was calculated by formula (12). In our calculations we have used the process cross-sections (see Figs. 2 and 3 ) and the threshold energy values $[8,12,13]$ similar to those used for the first model. The EEDF was assumed to be the Maxwellian distribution function. It should be noted that in real experimental conditions the EEDF can substantially differ from the Maxwellian. The calculations of the water molecule ionization cost versus electron temperature [5] have shown that the influence of the EEDF on $W$ is substantial at temperatures below $10 \mathrm{eV}$. At higher electron temperatures the ionization cost is weakly dependent on the EEDFs used in the calculations. The calculation data on the $\mathrm{OH}$ ionization cost are given in Fig. 5. For comparison, the same figure gives the data of ref. [5] for $\mathrm{H}_{2} \mathrm{O}$ (EEDF, Maxwellian). As it is shown in Fig. 5, the ionization cost for $\mathrm{H}_{2} \mathrm{O}$ is somewhat higher than for $\mathrm{OH}$, except for the temperature region between $\sim 5$ to $10 \mathrm{eV}$, where the $W$ values for $\mathrm{H}_{2} \mathrm{O}$ and $\mathrm{OH}$ are close. In this temperature range, more than $50 \%$ of the energy consumption goes to ionization (the first term of equation (12), the values $E_{i z ; j}, K_{i z, j}$ for both molecules are sufficiently close). The calculation results are discussed in more detail below. For the Maxwellian EEDF and the temperature $T_{e}=100 \mathrm{eV}$, the $W$ value for $\mathrm{H}_{2} \mathrm{O}$ and $\mathrm{OH}$ is determined to be 16.85 and $14.5 \mathrm{eV}$, respectively.

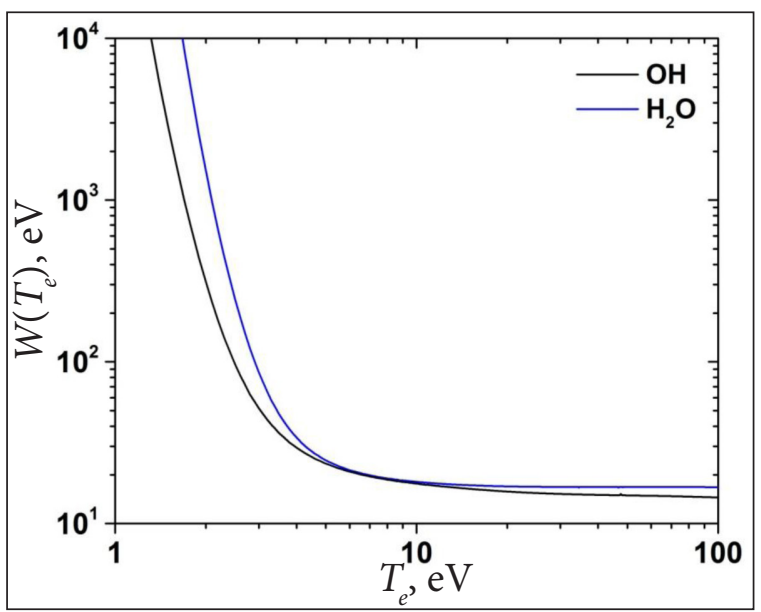

Fig. 5. Mean energy per electron-ion pair for $\mathrm{OH}$ and $\mathrm{H}_{2} \mathrm{O}$ on the electron temperature

The present calculations based on the two models with the use of the same initial data sets (see Figs. 4, 5) have shown that the dependence of the $\mathrm{OH}$ ionization cost on the electron energy (temperature) exhibits the general tendency, viz., the cost increase as the electron energy (temperature) is reduced. The behaviour of the $W$ curve is related to the ionization cross-section, that being very typical when using the model with 
a monoenergetic electron flow (beam), where the ionization cost maximum is observed at electron energy close to the ionization potential. Unlike the model with a monoenergetic electron flow (beam), taking into account of the EEDF in the plasma gives a somewhat lower ionization cost value. In this case, an essential increase in $W$ is observed at the electron temperature slightly below the ionization potential ( $10 \mathrm{eV}$, see Fig. 5). This is due to the decrease in the number of electrons capable for direct ionization of the molecule, and hence, due to increasing radiation losses.

The comparison between the $W$ values given by both models for $\mathrm{H}_{2} \mathrm{O}$ and $\mathrm{OH}$ shows a somewhat larger $W$ value for $\mathrm{H}_{2} \mathrm{O}$ than for $\mathrm{OH}$, whereas the $\mathrm{H}_{2} \mathrm{O}$ ionization potential $(12.621 \mathrm{eV})$ is lower than the $\mathrm{OH}$ ionization potential $(13.017 \mathrm{eV})$. This difference between the calculated data for $\mathrm{H}_{2} \mathrm{O}$ and $\mathrm{OH}$ may be attributed to several factors at once. First, unlike the $\mathrm{H}_{2} \mathrm{O}$ case, the ionization cost calculations for $\mathrm{OH}$ took into account a rather limited set of process cross-sections, because of lack of data in the literature. Secondly, the excitation cross-sections for $\mathrm{OH}$ electronic levels were calculated by the approximation formula, and therefore, may be under- or over-estimated. Comparison of the present excitation cross-sections with other experimental or calculated data appears impossible because of their absence. Thus, the consideration of additional electron-energy loss channels in future calculations should evidently lead to some increase in the calculated ionization cost values for $\mathrm{OH}$.

\section{CONCLUSIONS}

The present $\mathrm{OH}$ ionization cost calculations, based on two models, with the use of the same initial data sets, and the comparison with $\mathrm{H}_{2} \mathrm{O}$ ionization cost have shown a somewhat higher $W$ value for $\mathrm{H}_{2} \mathrm{O}$ than for $\mathrm{OH}$.

The calculation in the framework of the model considering the passage of a monoenergetic electron flow (beam) of energy 15 to $1000 \mathrm{eV}$ through the medium has demonstrated that for electron energy of $1000 \mathrm{eV}$ the ionization cost for $\mathrm{H}_{2} \mathrm{O}$ and $\mathrm{OH}$ makes $25.26 \mathrm{eV}$ and $21.65 \mathrm{eV}$, respectively.

We have considered the model taking into account the Maxwell and electron energy distribution functions at temperatures ranging from 3 to
$100 \mathrm{eV}$. At the electron temperature $T_{e}=100 \mathrm{eV}$, the calculation showed the $W$ values to be $16.85 \mathrm{eV}$ and $14.5 \mathrm{eV}$ for $\mathrm{H}_{2} \mathrm{O}$ and $\mathrm{OH}$, respectively.

Received 1 March 2017 Accepted 15 May 2017

\section{References}

1. Bruggeman P. J., Kushner M. J., Locke B. R., et al. Plasma-liquid interactions: a review and roadmap. Plasma Sources Science and Technology. 2016. Vol. 25. No. 5. P. 053002.

2. Locke B. R., Mededovic Thagard S. Analysis and review of chemical reactions and transport processes in pulsed electrical discharge. Plasma formed directly in liquid water. Plasma Chemistry and Plasma Processing. 2012. Vol. 32. No. 5. P. 875-917.

3. Liu D. X., Bruggeman P., Iza F., et al. Global model of low-temperature atmospheric-pressure $\mathrm{He}+\mathrm{H}_{2} \mathrm{O}$ plasmas. Plasma Sources Science and Technology. 2010. Vol. 19(2). P. 025018.

4. Kovtun Yu. V., Skibenko E. I., Yuferov V. B. Calculation and comparative analysis on the value of water molecule ionization in the pulsed electric discharge. Proceedings of the XVI-th International Conference on Physics of Pulse Discharges in Condensed Media, Mykolaiv, 2013 August 19-22. P. 30-33 (in Russian).

5. Kovtun Yu. V. Mean energy of water molecule ionization by electron impact. Technical Physics. 2015. Vol. 60. No. 8. P. 1110-1118.

6. Kovtun Yu. V. Energy expenditure for water molecule ionization by electron impact in weakly ionized plasma. Ukrainian Journal of Physics. 2016. Vol. 61. No. 1. P. 12-21.

7. Itikawa Y. Molecular Processes in Plasmas. Collisions of Charged Particles with Molecules. Springer Berlin Heidelberg New York, 2007. 194 p. ISBN 978-3-540-72609-8.

8. Ruscic B., Wagner A. F., Harding L. B., et al. On the enthalpy of formation of hydroxyl radical and gas-phase bond dissociation energies of water and hydroxyl. The Journal of Physical Chemistry A. 2002. Vol. 106. No. 11. P. 2727-2747.

9. Joshipura K. N., Vinodkumar M. Electron scattering cross sections with $\mathrm{HF}, \mathrm{OH}, \mathrm{NH}$ and $\mathrm{CH}$ 
molecules. Physics Letters A. 1997. Vol. 224. No. 6. P. 361-366.

10. Joshipura K. N., Vinodkumar M., Patel U. M. Electron impact total cross sections of $\mathrm{CH}_{x}, \mathrm{NH}_{x}$ and $\mathrm{OH}$ radicals vis-à-vis their parent molecules. Journal of Physics B: Atomic, Molecular and Optical Physics. 2001. Vol. 34. No. 4. P. 509-519.

11. Sobrinho A. M. C., Lozano N. B. H., Lee M.-T. Elastic and absorption cross sections for electron-hydroxyl radical collisions. Physical Review A. 2004. Vol. 70. No. 3. P. 032717.

12. Xiushan Cheny, Morgan L. A. Low-energy electron scattering from the $\mathrm{X}^{2} \Pi$ state of the $\mathrm{OH}$ molecule. Journal of Physics B: Atomic, Molecular and Optical Physics. 1997. Vol. 30. No. 16. P. 3709-3717.

13. Ewine F. van Dishoeck, Dalgarno A. Photodissociation processes in the $\mathrm{OH}$ molecule. The Journal of Chemical Physics. 1983. Vol. 79. No. 2. P. 873-888.

14. Riahi R., Teulet Ph., Ben Lakhdar Z., Gleizes A. Cross-section and rate coefficient calculation for electron impact excitation, ionisation and dissociation of $\mathrm{H}_{2}$ and $\mathrm{OH}$ molecules. The European Physical Journal D. 2006. Vol. 40. No. 2. P. 223230.

15. Drawin H.-W. Zur formelmäßigen darstellung der ionisierungsquerschnitte gegenüber elektronenstoß. Zeitschrift für Physik. 1961. Vol. 164. No. 5. P. 513-521.

16. Drawin H.-W., Emard F. Instantaneous population densities of the excited levels of hydrogen atoms and hydrogen-like ions in plasmas. Physica. 1977. Vol. 85C. No. 2. P. 333-356.

17. Deutsch H., Becker K., Mark T. D. A modified additivity rule for the calculation of electron im- pact ionization cross-section of molecules $\mathrm{AB}_{\mathrm{n}}$. International Journal of Mass Spectrometry and Ion Processes. 1997. Vol. 167/168. P. 503-517.

18. Tarnovsky V., Deutsch H., Becker K. Electron impact ionization of the hydroxyl radical. Journal of Chemical Physics. 1998. Vol. 109. No. 3. P. 932-936.

19. Kim Y.-K., Rudd M. E. Binary-encounter-dipole model for electron-impact ionization. Physical Review A. 1994. Vol. 50. No. 5. P. 3954-3967.

20. Kim Y.-K., Irikura K. K. Electron-Impact ionization cross sections for polyatomic molecules, radicals, and ions. AIP Conference Proceedings. Vol. 543. No. 1. P. 220-241.

21. Khare S. P. Mean energy expended per ion pair by electrons in atmospheric gases. Journal of Physics B: Atomic, Molecular and Optical Physics. 1970. Vol. 3. No. 7. P. 971-975.

22. Janev R. K., Post D. E., Langer W. D., et al. Survey of atomic processes in edge plasmas. Journal of Nuclear Materials. 1984. Vol. 121. P. 10-16.

23. Lee C., Lieberman M. A. Global model of Ar, $\mathrm{O}_{2}, \mathrm{Cl}_{2}$, and $\mathrm{Ar} / \mathrm{O}_{2}$ high-density discharges. Journal of Vacuum Science and Technology A. 1995. Vol. 13. No. 2. P. 368-380.

24. Ju-Hwan K. U., Young-Kwang L. E. E., ChinWook Chung. Measurement of the total energy losses per electron-ion lost in various mixed gas inductively coupled plasmas. Physics of Plasmas. 2010. Vol. 17. No. 4. P. 043508.

25. Young-Kwang L. E. E., Ju-Hwan K. U., ChinWook Chung. Measurements of the total energy lost per electron-ion pair lost in low-pressure inductive argon, helium, oxygen and nitrogen discharge. Plasma Sources Science and Technology. 2011. Vol. 20. No. 1. P. 015005. 
Yurii V. Kovtun

VIDUTINĖS ELEKTRONŲ ENERGIJOS, REIKALINGOS JONŲ PORAI VANDENYJE IR HIDROKSILUI RADIKALUOSE GAUTI, SKAIČIAVIMAI IR PALYGININAMOJI ANALIZE்

\section{Santrauka}

Fizikinių ir cheminių procesų tyrimai vykstant vandens molekulių sąveikai su įvairiomis dalelèmis (elektronais, jonais, fotonais, kt.) yra ypač svarbūs ir įdomūs sprendžiant plataus spektro fundamentinių ir taikomųjų mokslo sričių problemas: astrofizikos, radiacinès fizikos, chemijos ir biologijos, plazmos fizikos ir kt. Viena iš šių sričių, kelianti didelị susidomėjimą žemos temperatūros plazmos fizikoje ir taikant technologijas, apima tyrimus, susijusius su elektros išlydžiu skystoje terpejje ir virš jos paviršiaus. Kuriant technologijas, kuriose panaudojamas elektros išlydžio skystyje arba virš jo paviršiaus principas, viena iš svarbių užduočių yra nustatyti pagrindines bendras energijos sąnaudas procesui užtikrinti ir kontroliuo- ti. Viena iš svarbiausių energijos sąnaudos rūšių yra energija, reikalinga vandens molekulès jonizacijai ivvykti elektronų pluošto pagalba arba „Jonizacijos sąnaudos" $W$. Jonizacijos sąnaudos elektronų pluoštu yra dažniausiai apibūdinamos kaip vidutinè energija, reikalinga elektronui, kad sąveikos su vandens molekule metu medžiagoje susiformuotų nauja jonų-elektronų pora.

Straipsnyje pateikti vandens ir hidroksilo radikalų jonizacijos dèl elektronų sąnaudų, grịstų dviem modeliais, skaičiavimo rezultatai. Skaičiavimai paremti monoenerginių elektronų srautu, kurių energija kinta nuo 14 iki 1000 eV. Elektrono energijai esant $1000 \mathrm{eV}$, vandens molekulès jonizacijos sąnaudos siekia $W=25,26 \mathrm{eV}$ ir $W=21,65 \mathrm{eV}$ hidroksilo radikalui. Jonizacijos sąnaudos modelyje naudojant elektronų energijos pasiskirstymo funkciją plazmoje, kai $T_{e}=100 \mathrm{eV}$, vandens molekulei siekia $W=16,85 \mathrm{eV}$ ir $W=14,5 \mathrm{eV}$ hidroksilo radikalui.

Raktažodžiai: plazma, jonizacijos nuostoliai, hidroksilo radikalas, elektrono įtaka, vandens molekulè 